\title{
Synthesis and Polymerization of N,N'-[Bis(4,4'-Hydroxypropyl Methacrylate Phenylester) Pyromellitimide] Thermoset Polymer by Microwave Irradiation
}

\author{
Habib Saedi \\ Polymer Research Unit, College of Science, Al Mustansiriya University, Baghdad, Iraq \\ Email: habibmahtook@yahoo.com
}

Received 27 March 2016; accepted 19 April 2016; published 22 April 2016

Copyright (C) 2016 by author and Scientific Research Publishing Inc.

This work is licensed under the Creative Commons Attribution International License (CC BY).

http://creativecommons.org/licenses/by/4.0/

c) (i) Open Access

\begin{abstract}
A new difunctional monomer $\mathrm{N}, \mathrm{N}$ '-[bis(4,4'-hydroxypropyl methacrylate phenyl ester) pyromellitimide] (BHPMEPM), was synthesized by the reaction of the bis(4-carboxyphenyl)- $N, N^{\prime}-$-pyromellitimide acid (diacid-diimide), and two molar equivalents of glycidylmethacrylate (GMA). The reaction was carried out by microwave radiation. The presence of difunctional groups, double bond groups, makes the monomer a potential material for obtaining thermosetting product. The curing and thermal stability of the crosslinked products were studied by differential scanning calorimetry (DSC) and thermal gravimetric analysis (TGA) techniques. The difunctional monomer and its thermoset polymer were characterized by FT-IR, ${ }^{1} \mathrm{H}-\mathrm{FT}$-NMR and CHN elemental analysis.
\end{abstract}

\section{Keywords}

Microwave Radiation, Diacid-Diimide, Glycidylmethacrylate, Pyromellitimide, Poly(Ester-Imide), DSC, TG

\section{Introduction}

Due to their unique combination of properties like good dielectric strength and dimensional stability, Polyamides (PIs) as thermostats resins are constantly attract a wide interest [1]-[4]. As they are mainly used in the aerospace and electronic industries in the forms of films and moldings. Other uses for these polymers such as adhesives, composite matrices, coatings, foams, and gas separation membranes are rapidly increasing [5]-[11]. Most polyamides are insoluble in common organic solvents and intractable materials that do not melt before 
thermal decomposition and the reason behind that is their chain rigidity and strong interaction. To overcome this and increase processability, structural modification is done to increase the solubility in solvents or to decrease the melting temperatures. The chemical modifications of polyamides done by two different ways syntheses of poly(ester-imide)s with approachable transition temperatures [12]-[14] and poly(amid-imide)s with good solubility in a common solvent [15] [16]. To obtain polyesters there are two techniques which usually used first: interfacial polymerization reaction between dicarboxyliccid chlorides and diols; second: acid or phenyl ester exchange reaction of acetate or ester of the acids under critical conditions such as high temperature and reduced pressure. In these above techniques monomers like acid chlorides, acetates and esters should kept ready before polymerization [17]. Since many years ago, microwave technology played a vital role in synthesis of organic compounds and grasped wider attention. It is found to be rapid and more effective than routine methods of synthesis as it operates both microwave heating technology as well combinatorial chemistry applications [18]. By using microwave technology reactions are rapidly carried out and their products identified to be pure [19]. This paper is made to describe the microwave radiation auxiliary or help in synthesis of N,N'-[Bis(4,4'-hydroxypropyl methacrylate phenylester) pyromallitimide] (BHPMEPM), a novel monomer that possesses two polymerizable carbon-carbon double bonds, and its identification by FT-IR, NMR and elemental analysis. Its crosslinking polymerization, curing and thermal stability of the crosslinked product were also investigated by differential scanning and calorimetry and thermal analysis techniques.

\section{Experimental}

\subsection{Materials}

4-Aminobenzoic acid (p-ABA, Fluka), pyromellitic dianhydride (PMD, Aldrich), glycidylmethacrylate (GMA, Aldrich), triethylbenzylammonium chloride (TEBAC, Fluka), were purchased as analytical grade products and used as received. Pyridine (py, Fluka), was dried over solid $\mathrm{KOH}$ and fractionally distillated, dimethylformamide (DMF), was dried over $\mathrm{MgSO}_{4}$ followed by distillation under reduced pressure. All organic solvents were analytical grade products and were used as received or purified by distillation before use.

\subsection{Measurements}

${ }^{1} \mathrm{H}-\mathrm{NMR}$ spectra were obtained on a $500 \mathrm{MHz}$ FT-NMR spectrometer (Bruker Instruments, model Avance-III 500 , Germany) at room temperature using DMSO-d6as a solvent and TMS as an internal standard. FT-IR spectra were obtained with a JASCO model FT/IR 4200 in the $4000-400 \mathrm{~cm}^{-1}$ range on KBr pellets. Thermogravimetric analysis and differential scanning calorimetry (TGA and DSC) data were taken on a NETZSCH STA 449F3 System under $\mathrm{N}_{2}$ atmosphere at a rate of $10^{\circ} \mathrm{C} / \mathrm{min}$ for DSC and TGA. Elemental analysis were performed with a Perkin-Elmer $2400 \mathrm{CHN}$ analyzer.

\subsection{Syntheses}

The bifunctional monomer N,N'-[bis(4,4'-hydroxypropyl methacrylate phenyl ester) pyromellitimide] was synthesized in two steps from bis(4-4' carboxyphenyl)-N,N'-pyromellitimide acid (diacid-diimide) and glycidyl methacrylate (described below and shown in Scheme 1).

\subsection{Bis(4-Carboxyphenyl)-N,N'-Pyromellitimide Acid (Diacid-Diimide)}

This compound was prepared and characterized according to our previous works [20].

\subsection{Preparation of $\mathrm{N}, \mathrm{N}$ '-[Bis(4,4'-Hydroxypropyl Methacrylate Phenyl Ester) Pyromellitimide] (BHPMEPM)}

Mixtures of $4.563 \mathrm{~g}$ ( $1 \mathrm{mmol})$ of diacid-diimide, $2.843 \mathrm{~g}(2 \mathrm{mmol})$ of GMA were located in $100 \mathrm{~mL}$ RBF provided with a condenser and a magnetic stirrer, overlayered with $50 \mathrm{~mL}$ dry DMF. The RBF was flashed with nitrogen and microwave irradiated (power input: $600 \mathrm{~W}$ ) for 15 minutes. The small amount of unreacted diaciddiimide was removed from the reaction mixture by filtration. The effluent obtained was evaporated under reduced pressure to its half original volume and the viscous product precipitated by distilled water. The precipitate was filtered, washed twice with $100 \mathrm{~mL}$ warm distilled water and dried under vacuum at $45^{\circ} \mathrm{C}$ for $48 \mathrm{~h}$. Yield $=$ 


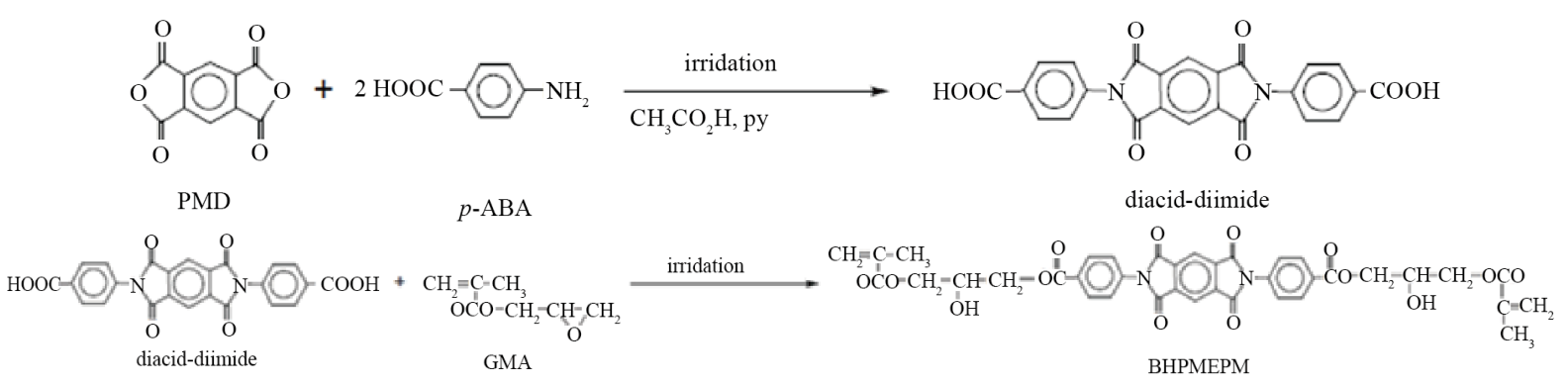

Scheme 1. Synthetic route of the compound BHPMEPM.

91\%. Anal. Calcd. for $\mathrm{C}_{38} \mathrm{H}_{32} \mathrm{~N}_{2} \mathrm{O}_{14}$ : C, 61.61; H, 4.35; N, 3.83. Found: C, 61.56; H, 4.41; N, 3.87\%. IR (KBr) $\tilde{v} \quad 3476,2891,2954,1780,1725,1375,722,1272,1172,1630,1604,1515,1454 \mathrm{~cm}^{-1}$. ${ }^{1} \mathrm{H}-\mathrm{NMR}$ (DMSO-d6) $\delta$ : 7.54 - 8.49, 5.76 - 6.18, 5.48, 4.26, 3.65, $1.82 \mathrm{ppm}$.

\subsection{The Curing of Monomer BHPMEPM}

$0.2 \mathrm{~g}$ of BHPMEPM was dissolved in $5 \mathrm{~mL}$ of DMSO at room temperature, the solution was cast on a quartz plate, and then dried in vacuo. The isolated monomer films were cured at $180^{\circ} \mathrm{C}$ for $2 \mathrm{~h}$, in vacuo. After curing, the film was used for the IR and TG.

\section{Results and Discussion}

\subsection{Synthesis and Structure of Products}

\subsubsection{Monomer Synthesis}

Diacid-diimide was synthesized from condensation reaction of aquimolar of pyromellitic dianhydride (PMD) with two aquimolar of $p$-amino benzoic acid ( $p$-ABA) in a mixture of glacial acetic acid and pyridine using microwave irradiation.

The difunctional monomer N,N'-[bis(4,4'-hydroxypropyl methacrylatephenyl ester) pyromellitimide] (BHPMEPM) was obtained through the reaction between aquimolar of bis(4-carboxyphenyl)-N,N'-pyromellitimide acid (diacid-diimide) and two aquimolar of glycidylmethacrylate (GMA) (Scheme 1).

The chemical structure of the bifunctional monomer BHPMEPM was confirmed by FT-IR, ${ }^{1} \mathrm{HNMR}$ spectroscopy and elemental analysis. In the FT-IR spectrum (Figure 1), the characteristic absorption band of oxirane ring from GMA, located at $913 \mathrm{~cm}^{-1}$ was absent and a sharp signal appeared at $3476 \mathrm{~cm}^{-1}$ signifying an associated hydroxyl group, indicating that the reaction between epoxy ring and carboxylic proton has taken place. The absorption band specific to the ester group $\mathrm{C}=\mathrm{O}$ is overlapped by the signal of the $\mathrm{C}=\mathrm{O}$ group from imide ring and exhibited at $1725 \mathrm{~cm}^{-1}$, the strong absorption due to the presence of cyclic imide linkages is shifted and located at $1780.9 \mathrm{~cm}^{-1}$. The signal specific to C-O- group, is presented in the 1172 to $1272 \mathrm{~cm}^{-1}$ range. The three signals located at 1454,1515 and $1604 \mathrm{~cm}^{-1}$ are assigned to the characteristic combined stretching and deformation of aromatic $\mathrm{C}=\mathrm{C}$ bonds from bis(4-carboxyphenyl)-N,N'-pyromellitimide acid moieties. The absorption bands specific to $\mathrm{CH}, \mathrm{CH}_{2}$ and $\mathrm{CH}_{3}$ from GMA moieties are observed at $2954 \mathrm{~cm}^{-1}$ and the signal specific to double bonds for methacrylic is located at $1629 \mathrm{~cm}^{-1}$.

Further characterization was performed with ${ }^{1} \mathrm{H}$ NMR. In ${ }^{1} \mathrm{H}$ NMR spectrum (Figure 2), the specific absorption bands characteristic to epoxy group at 2.6 and 2.8 ppm were not observed, but the signal specific to the new secondary $\mathrm{OH}$ group centered at $5.48 \mathrm{ppm}$ appeared, indicating that the addition of the carboxylic group to the epoxy group was completed. The methacrylic double bonds are located at 5.76 and 6.18 [21] and those ten aromatic protons due to diacid-diimide moieties observed at 7.52 - $8.30 \mathrm{ppm}$ chemical shift range.

\subsubsection{Chemical and Thermal Analysis of the Cured Resins}

The thermal behavior of the polymerization reaction of bifunctional monomer BHPMEPM was monitored by DSC scanning. The thermogram of the BHPMEPM is presented in (Figure 3).

It can be noticed that BHPMEPM shows one reaction exotherm depending on the reactivity of methacrylic two double bonds. 


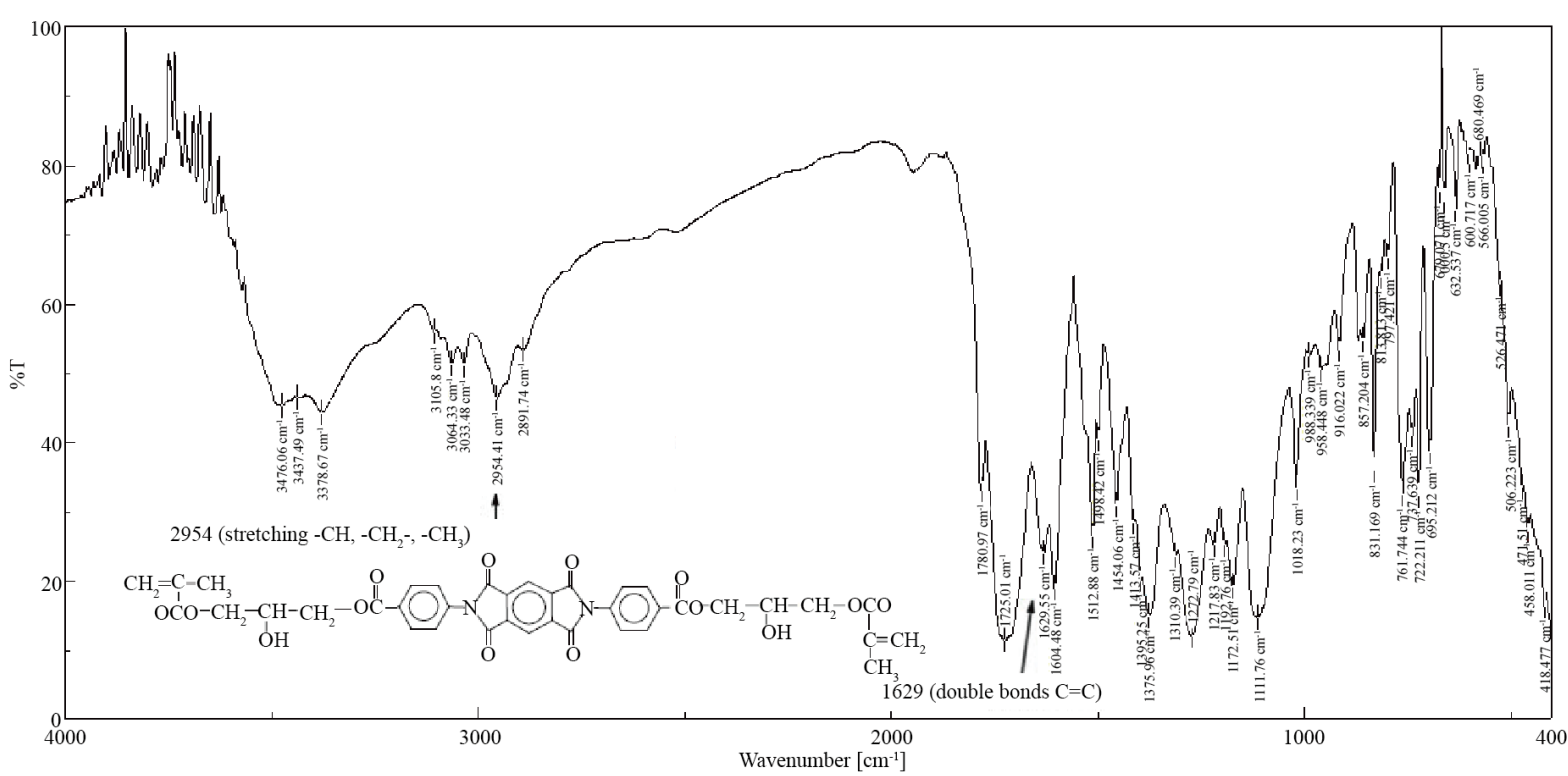

Figure 1. FT-IR of compound BHPMEPM.

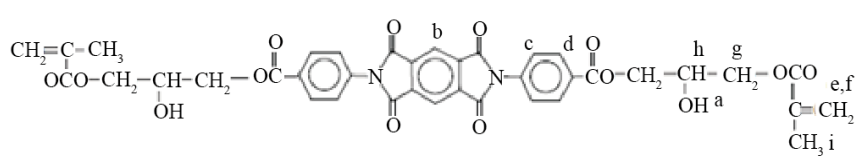

Current Data Parameters
NAME Jan13-2014

$\begin{array}{lc}\text { EXPNO } & 16 \\ \text { PROCNO } & 1\end{array}$

F2 - Acquisition Parameters

Date_ 20140112

Time $\quad 23.22$

$\begin{array}{lc}\text { INSTRUM } & \text { spect } \\ \text { PROBHD } & 5 \mathrm{~mm} \text { PABBO BB- }\end{array}$

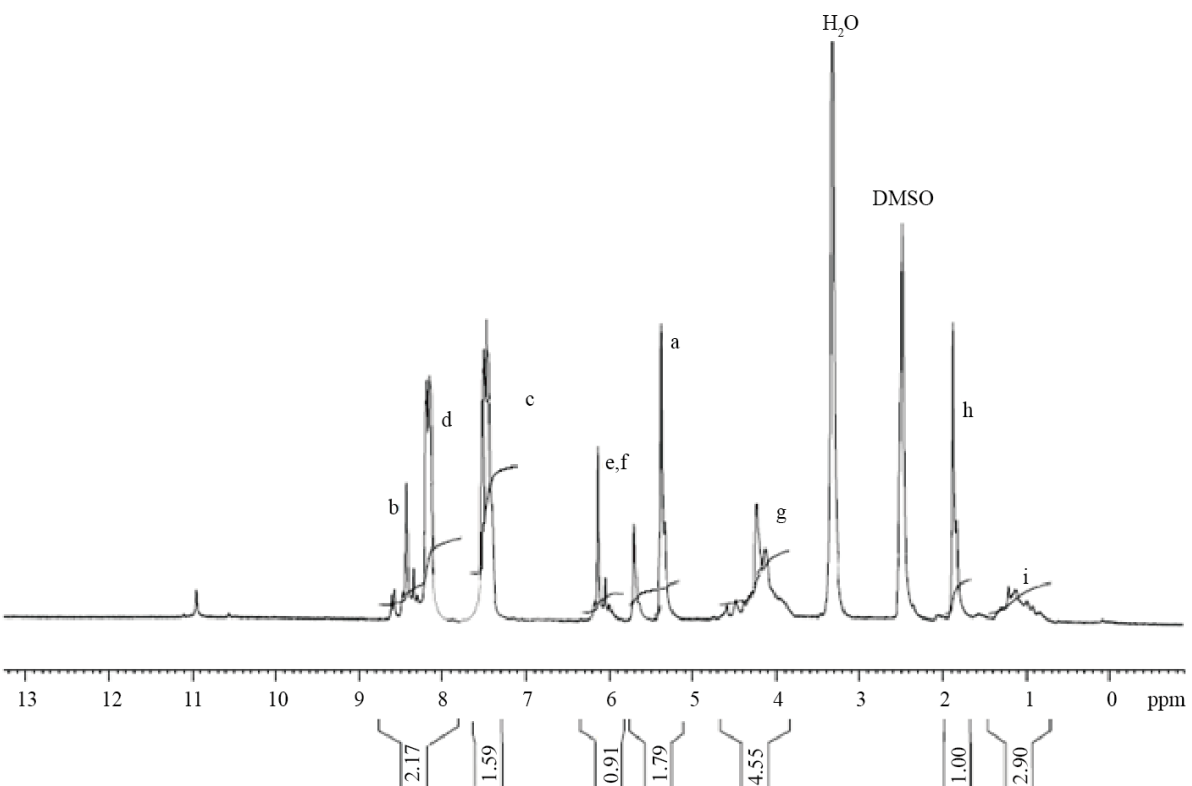
PULPROG Zg30 SOLVENT $\quad 32768$ DMSO $\begin{array}{lll}\text { NS } & 32 \\ \text { DS } & 2\end{array}$

$\begin{array}{ll}\text { DS } & 2 \\ \text { SWH } & 10330.578 \mathrm{~Hz}\end{array}$ $\begin{array}{lr} & 10330.578 \mathrm{~Hz} \\ \text { FIDRES } & 0.315264 \mathrm{~Hz}\end{array}$ $\begin{array}{lr}\text { FIDRES } & 0.315264 \mathrm{~Hz} \\ \mathrm{AQ} & 1.5860212 \mathrm{sec}\end{array}$ $\begin{array}{lc}\mathrm{AQ} & 1.58602 \\ \mathrm{RG} & 203\end{array}$

DW $\quad 48.400$ usec

DE $\quad 6.50$ usec

$\begin{array}{ll}\text { DE } & 6.50 \mathrm{usec} \\ \mathrm{TE} & 296.1 \mathrm{~K}\end{array}$ D1 $1.00000000 \mathrm{sec}$ $\begin{array}{lr}\text { TD0 } & 1.0000000\end{array}$ $=======$ CHANNEL fl $=======$ $\begin{array}{lc}\mathrm{NUCl} & 1 \mathrm{H} \\ \mathrm{P} 1 & 10.65 \mathrm{usc}\end{array}$ $\begin{array}{ll}\text { P1 } & 10.65 \mathrm{usec} \\ \text { PL1 } & 0.00 \mathrm{~dB}\end{array}$ $\begin{array}{ll}\text { PLlW } & 23.53637505 \mathrm{~W} \\ \text { SFO1 } & 500.1330885 \mathrm{MH}\end{array}$

F2 - Processing parameters SI $\quad 32768$ SF $500.1300000 \mathrm{MHz}$ WDW EM $\begin{array}{lc}\text { SSB } & 0 \\ \text { LB } & 0.30 \mathrm{~Hz}\end{array}$ $\begin{array}{lc}\text { GB } & 0 \\ \text { PC } & 1.00\end{array}$

Figure 2. ${ }^{1}$ H-FT-NMR spectra for BHPMEPM.

The curing reaction starts at around $163^{\circ} \mathrm{C}$ with a maximum of the exothermic peak at $180.2^{\circ} \mathrm{C}$. At about $195^{\circ} \mathrm{C}$, the curing is complete where the absence of exotherm indicates no post curing. The difunctional monomer BHPMEPM was crosslinked under $180^{\circ} \mathrm{C}$ for $2.0 \mathrm{~h}$ to give the thermoset resin (Scheme 2).

Figure 4 represents the IR spectrum of the crosslinked product, the absence of the signal of $\mathrm{CH}_{2}=\mathrm{C}_{\text {at }} 1629$ $\mathrm{cm}^{-1}$ indicates the occurrence of the methacrylic double bond polymerization. Also, the absorption due to the presence of other functional groups are exhibited at their characteristic absorption bands with small shifting. 


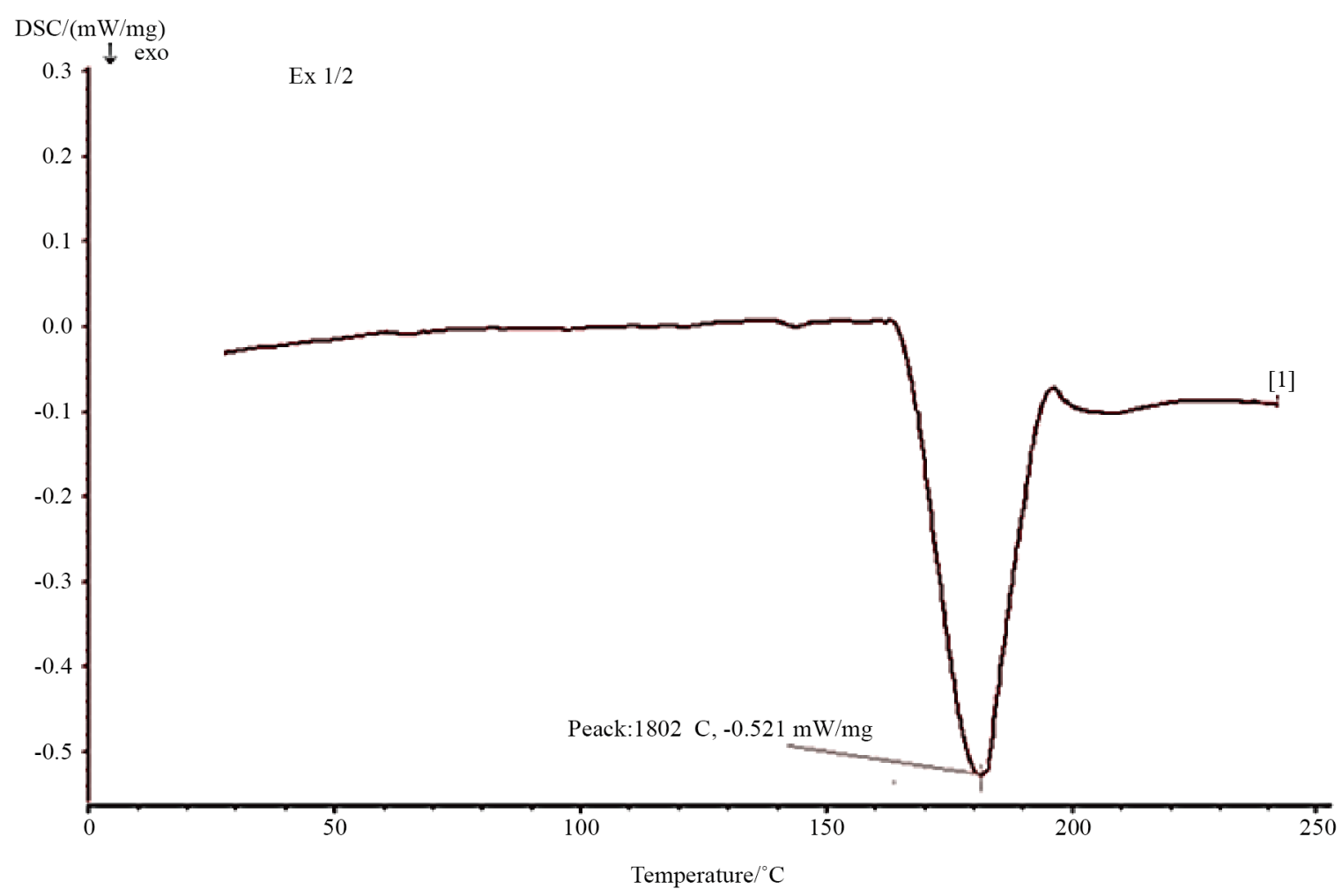

Figure 3. DSC Thermogram of BHPMEPM.

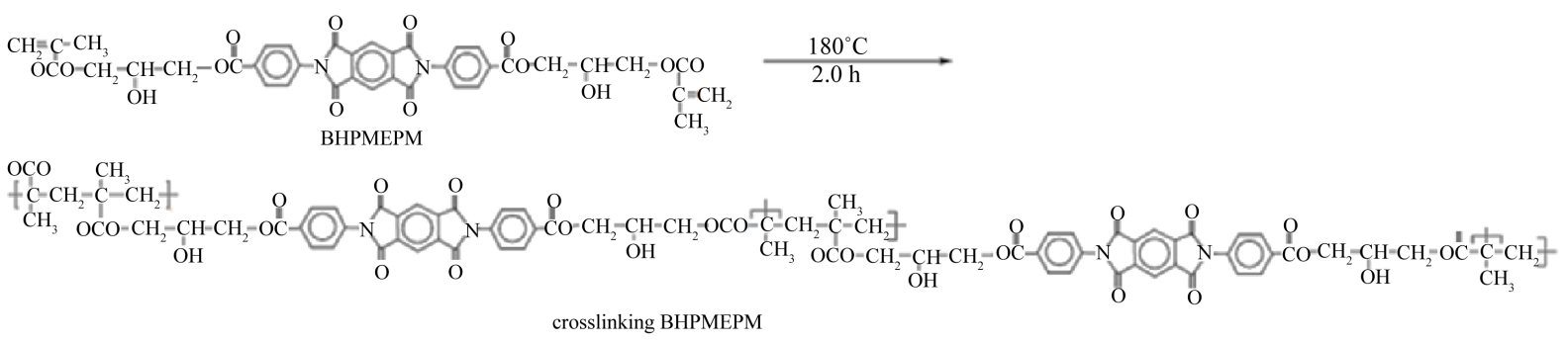

\section{Scheme 2. Probable crosslinking mechanism of BHPMEPM.}

The thermal stability and thermal degradation behavior of the cured bifunctional monomer BHPMEPM were examined by analysis of the thermogravimetric (TG-DTG) curve (Figure 5).

The TG of cured monomer BHPMEPM has typical pattern of thermograms, involved three steps of weight loss from $25^{\circ} \mathrm{C}$ to $800^{\circ} \mathrm{C}$. The first weight loss for cured product was observed from $230^{\circ} \mathrm{C}$ to $386^{\circ} \mathrm{C}$ with $37.47 \%$ loss weight. The second weight loss for the polymer occurred at the temperature range from $452.9^{\circ} \mathrm{C}$ to $571.3^{\circ} \mathrm{C}$ with $16.14 \%$ loss weigh. Finally, the third weight loss for the polymer occurred at the temperature range from $571.3^{\circ} \mathrm{C}$ to $730^{\circ} \mathrm{C}$ with $12.47 \%$ loss weigh. This result is comparable with the thermal analysis of poly(glycidyl methacrylate) which undergoes one step of weight loss, between 140 and $450^{\circ} \mathrm{C}$ [22] [23], proves the structure of the bifunctional monomer BHPMEPM and the effect of the pyromellitimide moieties in the increasing of the thermal stability of poly (glycidyl methacrylate). Also the TG scheme shows the temperature of $10 \%$ weight loss (T10) and the temperature of $50 \%$ weight loss (T50) are at $356^{\circ} \mathrm{C}$ and $473^{\circ} \mathrm{C}$ respectively.

\subsection{Solubility and Viscosity}

The polymer shows good solubility in aprotic polar solvents such as NMP, DMAc, DMF, and DMSO, while insoluble with common organic solvents such as tetrahydrofuran, chloroform, acetone and benzene. The polymer had good transparency and its inherent viscosity $(\eta$ inh) is $0.82 \mathrm{dL} / \mathrm{g}$. 


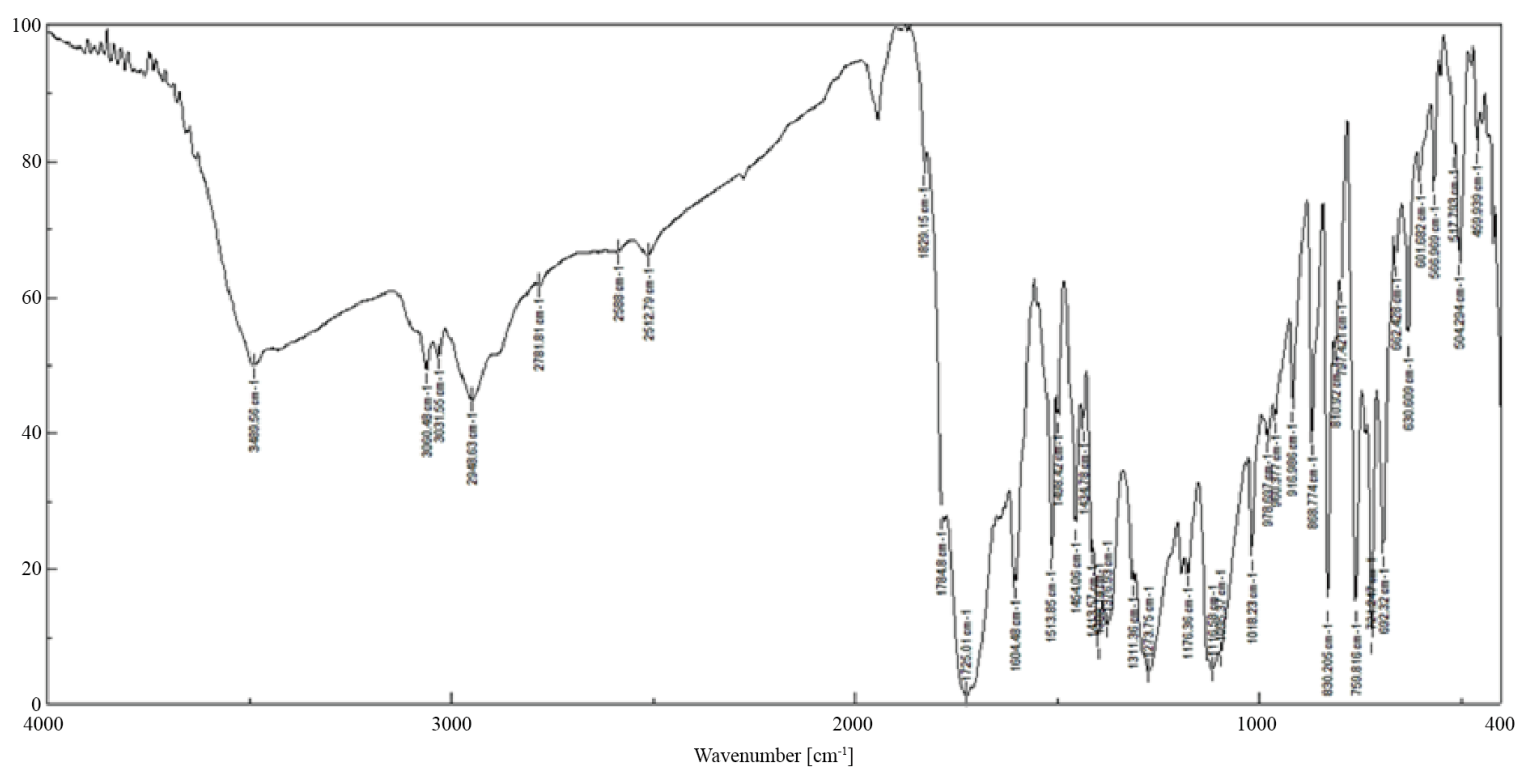

Figure 4. FT-IR of the cured difunctional monomer BHPMEPM.

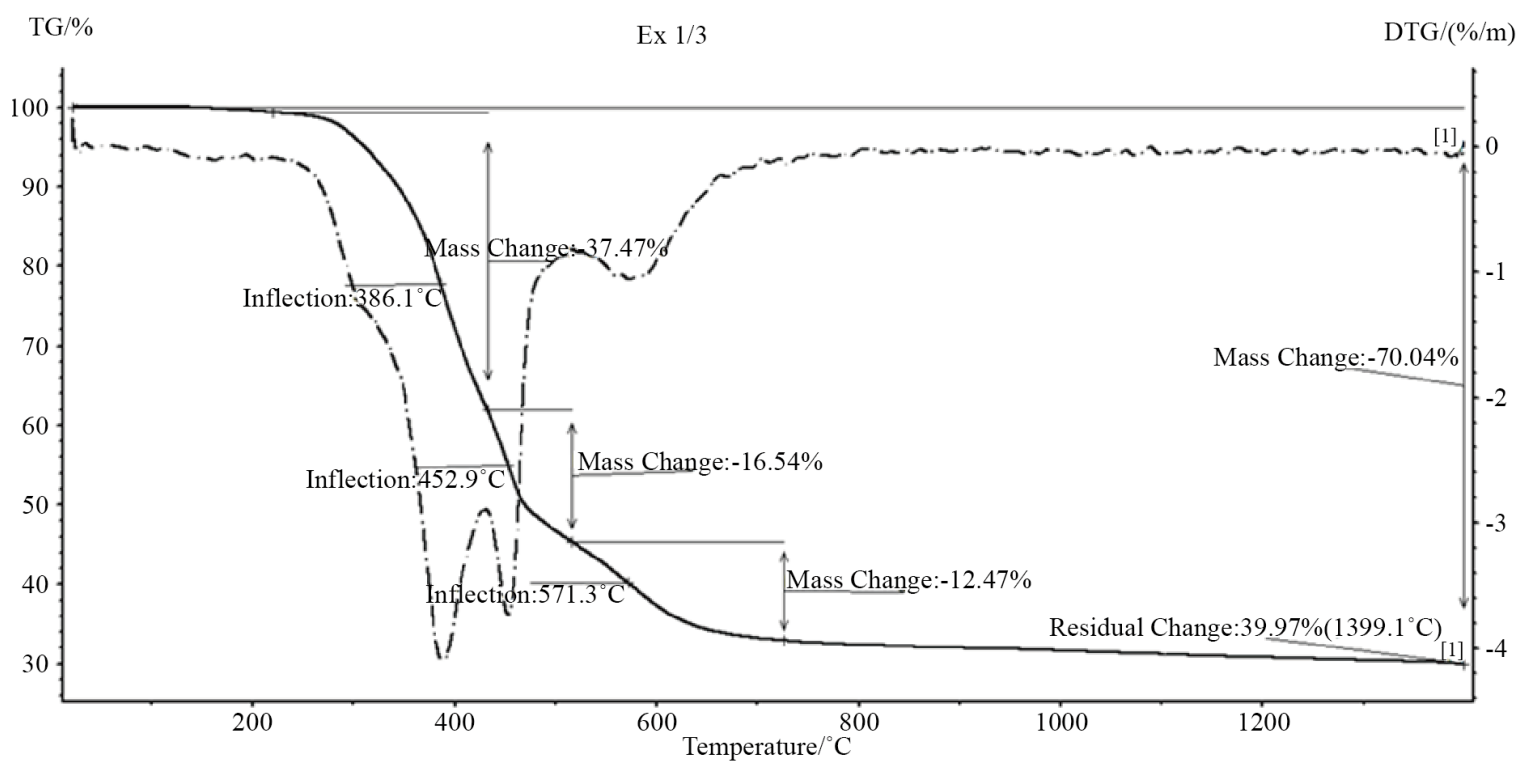

Figure 5. TG and DTG thermograms of crosslinked BHPMEPM.

\section{Conclusion}

The diacid-diimide was used as a building block of poly(imide-ester) by its reaction with glycidylmethacrylate to produce a new bifunctional monomer. The structure of this monomer was confirmed by FT-IR, ${ }^{1} \mathrm{H}$ FT-NMR, and elemental analysis. The curing reaction of this bifunctional monomer was monitored by DSC scanning which shows that one reaction exotherm represents the crosslinking cured product depending on the reactivity of methacrylic two double bonds with a maximum of the exothermic peak at $180.2^{\circ} \mathrm{C}$. The cured product shows good thermal properties and good solubility in aprotic polar solvents. The crosslinked products can be used as moulding compounds and encapsulating materials in electric or electronic industry.

\section{References}

[1] Sroog, C.E. (1996) History of the Invention and Development of the Polyimides. In: Ghosh, M.K. and Mittal, K.L., 
Eds., Polyimides: Fundamentals and Applications, Marcel Dekker, New York.

[2] Bessonov, M.I., Koton, M.M., Kudryavtsev, V.V. and Laius, L.A. (1987) Polyimides. Thermally Stable Polymers, Consultants Bureau, New York.

[3] Wilson, D., Stenzenzenberger, H.D. and Hergenrother, P.M. (1990) Polyimides. Blackie \& Son, Glasgow and London. http://dx.doi.org/10.1007/978-94-010-9661-4

[4] Spiliopoulos, I.K., Mikroyannidis, J.A. and Tsivgoulis, G.M. (1998) Rigid-Rod Polyamides and Polyimides Derived from 4,3”-Diamino-2',6'-Diphenyl-P-Terphenyl or Di(4-biphemyl)-P-Terphenyl and 4-Amino-4” Carboxy-2'-6'-Diphenyl-P-Terphenyl. Macromolecules, 31, 522-529. http://dx.doi.org/10.1021/ma9709664

[5] Mittal, K.L. (2003) Polyimides and Other High Temperature Polymers: Synthesis, Characterization and Applications. Vol. 2, VSP, Utrecht.

[6] Huang, S.J. and Hoyt, A.E. (1995) Synthesis of Soluble Polyimides. Trends in Polymer Science, 3, 262.

[7] Cella, J.A. (1992) Degradation and Stability of Polyimides. Polymer Degradation and Stability, 36, 99-110. http://dx.doi.org/10.1016/0141-3910(92)90145-U

[8] Volksen, W. (1994) Condensation Polyimides: Synthesis, Solution Behavior, and Imidization Characteristics. Advances in Polymer Science, 117, 111-164. http://dx.doi.org/10.1007/BFb0021198

[9] Takekoshi, T. (1990) Polyimides. Advances in Polymer Science, 94, 1-25. http://dx.doi.org/10.1007/BFb0043059

[10] Gohsh, M.K. and Mittal, K.L. (1996) Polyimides Fundamentals and Applications. Marcel Dekker, New York.

[11] Bessonov, M.I. and Zubkov, V.A. (1993) Polyamic Acids and Polyimides, Synthesis, Transformation and Structure. CRC Press, Boca Raton.

[12] Kricheldorf, H.R., Schwarz, G., Domschke, A. and Linzer, V. (1993) Liquid Crystalline Polyimides. 15. Role of Conformation and Donor-Acceptor Interactions for the Nematic Order of Poly(ester-imide)s. Macromolecules, 26, 5161-5168. http://dx.doi.org/10.1021/ma00071a028

[13] Kricheldorf, H.R. and Pakull, R. (1987) New Polymer Syntheses: 21. LC-Poly(ester imide)s Prepared from Trimellitic Acid, $\alpha, \theta$-diaminoalkanes and Various Hydroquinones or Dihydroxynaphthalenes. Polymer, 28, 1772-1778. http://dx.doi.org/10.1016/0032-3861(87)90023-1

[14] Yang, C.P. and Hsiao, S.H. (1989) Preparation of Poly(amide-imide)s by Means of Triphenyl Phosphite, 1. AliphaticAromatic Poly(amide-imide)s Based on Trimellitimide. Die Makromolekulare Chemie, 190, 2119-2131. http://dx.doi.org/10.1002/macp.1989.021900912

[15] Hsiao, S.H. and Yang, C.P. (1990) Preparation of Poly(amide-imide)s via the Phosphorylation Reaction. II. Synthesis of Wholly Aromatic Polyamide-Imides from $N$-[p-(or $m$-)carboxyphenyl]trimellitimides and Various Aromatic Diamines. Journal of Polymer Science Part A: Polymer Chemistry, 28, 1149-1159. http://dx.doi.org/10.1002/pola.1990.080280515

[16] de Abajo, J. and de la Campa, J.G. (1999) Processable Aromatic Polyimides. In: Kricheldorf, H.R., Ed., Progress in Polyimide Chemistry I, Advances in Polymer Science, Vol. 140, Springer, Berlin, 23-59. http://dx.doi.org/10.1007/3-540-49815-X_2

[17] Mallakpour, S. and Kolahdoozan, M. (2006) Preparation and Characterization of Novel Optically Active Poly(amideester-imide)s Based on Bis(p-aminobezoic acid)-Ntrimellitylimido-S-valine via Direct Polyesterification. Iranian Polymer Journal, 15, 307-315.

[18] Larhed, M. and Hallberg, A. (2001) Microwave-Assisted High-Speed Chemistry: A New Technique in Drug Discovery. Drug Discovery Today, 6, 406-441. http://dx.doi.org/10.1016/s1359-6446(01)01735-4

[19] Mingos, D.M.P. and Whittaker, A.G.P. (1997) Microwave Dielectric Heating Effects in Chemical Synthesis. In: Van Malik, R.V. and Hubbard, C.D., Eds., Chemistry under Extreme or Non-Classical Conditions, John Wiley and Sons and Spektrum Akade-mischer Verlag Co-Publication, New York and Heidelberg, 479-514.

[20] Saedi, H. (2014) Using Microwave Irradiation for Synthesis of Imides Consist of Pyromellitimide. Journal of Advances in Chemistry, 10, 2276-2282.

[21] Bakhshi, H., Zohuriaan-Mehr, M.J., Bouhendi, H. and Kabiri, K. (2009) Spectral and Chemical Determination of Copolymer Composition of Poly(butyl acrylate-co-glycidyl methacrylate) from Emulsion Polymerization. Polymer Testing, 28, 730-736. http://dx.doi.org/10.1016/j.polymertesting.2009.06.003

[22] Hanifah, S.A., Hamzah, N. and Yook, H.L. (2013) Rapid Synthesis of Magnetic Microspheres Poly(glycidyl methacrylate-co-styrene) by Photopolymerization. Sains Malaysiana, 42, 487-493.

[23] Vijayanand, P.S., Kato, S., Satokawa, S. and Kojima, T. (2007) Homopolymer and Copolymers of 4-nitro-3-methylphenyl Methacrylate with Glycidyl Methacrylate: Synthesis, Characterization, Monomer Reactivity Ratios and Thermal Properties. European Polymer Journal, 43, 2046-2056. http://dx.doi.org/10.1016/j.eurpolymj.2007.01.042 